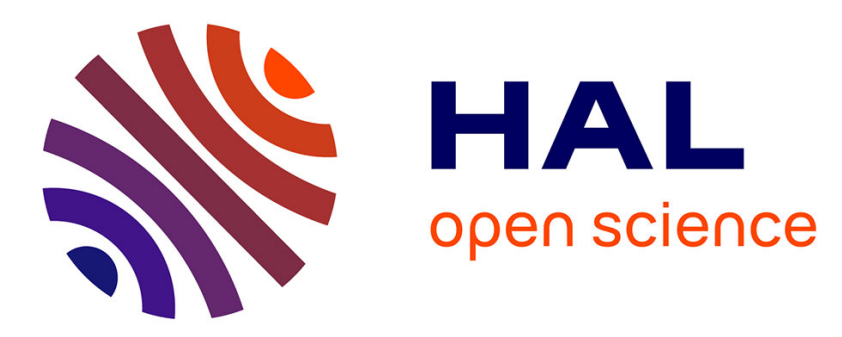

\title{
Design of Space Truss Based Insulating Walls for Robotic Fabrication in Concrete
}

Romain Duballet, Olivier Baverel, Justin Dirrenberger

\section{To cite this version:}

Romain Duballet, Olivier Baverel, Justin Dirrenberger. Design of Space Truss Based Insulating Walls for Robotic Fabrication in Concrete. Klaas De Rycke, Christoph Gengnagel, Olivier Baverel, Jane Burry, Caitlin Mueller, Minh Man Nguyen, Philippe Rahm, Mette Ramsgaard Thomsen. Humanizing Digital Reality, Springer, pp.453-461, 2017, 978-981-10-6610-8. 10.1007/978-981-10-6611-5_39 . hal01592008

\section{HAL Id: hal-01592008 \\ https://hal.science/hal-01592008}

Submitted on 11 Oct 2017

HAL is a multi-disciplinary open access archive for the deposit and dissemination of scientific research documents, whether they are published or not. The documents may come from teaching and research institutions in France or abroad, or from public or private research centers.
L'archive ouverte pluridisciplinaire HAL, est destinée au dépôt et à la diffusion de documents scientifiques de niveau recherche, publiés ou non, émanant des établissements d'enseignement et de recherche français ou étrangers, des laboratoires publics ou privés. 


\title{
Design of Space Truss Based Insulating Walls for Robotic Fabrication in Concrete
}

\author{
Romain Duballet ${ }^{1,3(\bowtie)}$, Olivier Baverel ${ }^{1}$, and Justin Dirrenberger ${ }^{2,3}$ \\ ${ }^{1}$ Laboratoire Navier, UMR 8205, Ecole des Ponts, IFSTTAR, CNRS, UPE, \\ Champs-sur-Marne, France \\ romain.duballet@gmail.com \\ 2 Laboratoire PIMM, Ensam, CNRS, Cnam, 151 bd de l'Hôpital, 75013 Paris, \\ France \\ 3 XtreeE, Immeuble Le Cargo, 157 bd Macdonald, 75019 Paris, France
}

\begin{abstract}
This work focuses on the design of ultra-light concrete walls for individual or collective housing, the normative context being constrained masonry. It is stated that current block work building is very inefficient in terms of quantity of concrete used for cinderblocks and mortar joints, and with regards to thermal insulation. Here is proposed a robotic manufacturing technique based on mortar extrusion that allows producing more efficient walls. First we present the fabrication concept, then design criteria for such objects. In the last section we show a comparative study on different geometries. We conclude with a discussion on the performances of this proposed building system.
\end{abstract}

Keywords: Concrete printing $\cdot$ Robotic construction $\cdot$ Space truss

\section{Introduction}

Cement consumption is one of the major environmental issues of our century. Concrete is now the most used manufactured material in the world, with 6 billion cubic meters produced every year. Considering current and future needs in housing, it is not meant to decrease. Between 2011 and 2013, China has produced more concrete (6.6 Gigatons) than the US did during the whole twentieth century (4.5 Gigatons). ${ }^{1}$ Given its polluting impact, it is now crucial to learn how to build with less cement.

In the past two years, numerous studies have flourished on the topic of robotic mortar extrusion, mainly oriented toward what is denoted by concrete 3D printing. This term refers to a family of constructive approaches consisting in progressively stacking relatively small quantities of specifically formulated mortar to fabricate a given form. The first publication on such strategies go back to Pegna (1997) and its first explicit mention to Khoshnevis (2004). If one can find reviewed work on the associated fabrication processes (Lim et al. 2011, 2012; Gosselin et al. 2016), concrete formulation (Le et al. 2012a, b; Feng et al. 2015) or robotic control (Bosscher et al. 2007), few has been done to prove the true interest of concrete printing in construction. The two main aspects often mentioned about these techniques are the speed and ease offered to

${ }^{1}$ Source: USGS Cement Statistics 1900-2012; USGS, Mineral industry of China 1990-2013. 
building, on one hand, and the new attainable geometrical freedom, on the other hand. If Pegna's original paper focused on the concept of "free-form construction", emphasizing the interest of geometrical freedom, most today's application of concrete printing exhibits nearly traditional constructive elements. If the fabrication process is in itself innovative, and very promising for the future of construction work, its impact on the fabricated object still remains marginal. Our position on such matter is that such technologies should be strongly linked with their final usage from the beginning. The problem that we address here is the following: how this technology can allow great reduction of overall concrete consumption in the building industry?

In this paper we present a novel constructive approach based on robotic extrusion of mortar. The final goal is the production of structural-insulating walls of new performances. Some of the co-authors presented a work of similar purpose in DMS 2015 (Duballet et al. 2015), where the studied process involved extrusion of cement paste mixed with polystyrene beads. Here the mortar is extruded only for its structural performances, but we take advantage of a novel assembly strategy of insulating blocks, that also serve as support for the printing.

\section{Masonry with Robotic Mortar Extrusion}

Constrained masonry, the assembly technique of breeze blocks and mortar restrained in a reinforced concrete frame, is a very popular building system, especially for individual and collective housing, for it is at once cheap, fast and easily implemented. From a purely mechanical point of view, it is however quite inefficient. In the case of a one or two-storey house, the need in mechanical resistance for the wall itself, considering the presence of the reinforced concrete frame, is indeed far lower than the breeze blocks/mortar system can provide. The main role of this staking is in fact to allow solid continuity between the concrete frames, for bracing purpose and to act as separating wall. Up to a limit, it could be said that the mortar between the blocks is the only needed element to provide resistance. Such considerations leads us to the idea of assembling insulating blocks instead of breeze blocks, leaving the mechanical role to the mortar in between, and getting thermal performances in addition.

The new system for the wall is now a generalization of the previous one: a continuous spatial structure in mortar, and thermic insulation in the negative space. The three questions to answer are then (a) which shape for the mortar structure, (b) can it be easily fabricated, and (c) are the overall performances meeting the expectations?

The key aspect of the technique is to assemble specifically shaped insulating blocks by printing a mortar joint at the edges location (Fig. 1). The mortar is extruded through a nozzle controlled by a robotic arm, as described in Gosselin et al. (2016). The mortar acts as joint for the insulating blocks, while they act as printing support for the mortar. It can be decomposed into the following steps:

1. Insulating blocks fabrication

For prototyping in our laboratory we will work with extruded polystyrene panels from which the blocks will be extracted, thanks to a hot-wire robotic cutting process. Other ways of making the blocks can be thought of, like molding of mineral 

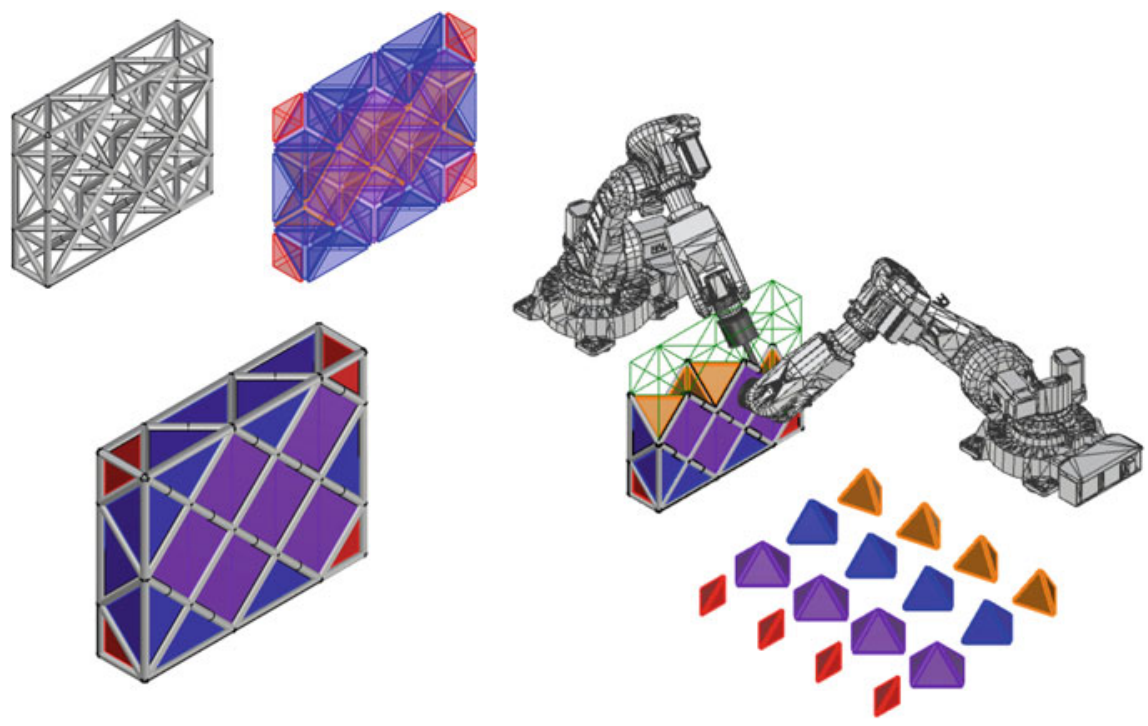

Fig. 1. Concept of fabrication

foam for instance. The blocks are shaped into polyhedra, the edges of which are replaced by a channel to be filled with mortar.

2. Insulating blocks assembly

The blocks are assembled by a pick and place robot. They form a layer of printing support for the mortar to be extruded on. This step is repeated for each layer of blocks, and alternating with step 3.

3. Mortar extrusion

The mortar is extruded by a printing system (Gosselin et al. 2016). The already deposited blocks channels are filled by the printed truss members, on which will be brought the next insulating blocks (back to step 2).

4. Confining elements

Tie columns and ring beams that will ensure masonry confinement.

This system brings some shape constraints for the blocks, they must form a space tessellation, the edges of which will form a mortar space truss. Since this truss is printed on the blocks, it must not be done too close to verticality. In addition, for assembly purpose, the number of crossing elements at each nodes must be limited. We have conducted a comparison of different space tessellations. In the next section we present our design strategy, and the last section deals with the results.

\section{Design Criteria}

Thanks to this manufacturing technique it is realistic to hope for ultra-light space truss walls that drastically reduce concrete consumption while reaching current needs in thermal insulation. Three constructive solutions are used as a comparison, traditional 
block work wall with an additional insulating layer, a contemporary solution for walls based on cellular concrete blocks and a pre-wall system where concrete is cast between layers of insulating material. The overall size of the wall is fixed $(2.5 \mathrm{~m} \times 3 \mathrm{~m})$, as well as a goal U-value for thermal efficiency of $0.09 \mathrm{~W} \mathrm{~m}^{-2} \mathrm{~K}$, corresponding to the lower side of 2020 Thermal Regulations (imposing a U-value for the wall between 0.15 and $0.1 \mathrm{~W} \mathrm{~m}^{-2} \mathrm{~K}$ ).

We have conducted a parametric study on such walls performances, taking into account both mechanical and thermal performances. The study is made on Grasshopper, and the structural analysis performed with Karamba 3D. We work with a mortar of relatively high compressive value, as it can be advised for such light structures. Material performances are to be taken with care for dimensioning, because the extrusion process can limit its final quality. Our normative context is constrained masonry, governed by Eurocode 6, which does not specifically give a value for calculated maximum tensile stress. We choose to work with the Eurocode 2 value $f_{t}=0.3$ $\mathrm{f}_{\mathrm{ck}}^{2 / 3}$ taking an additional security factor into account. Our hypothesis for calculus is a C90/105 concrete, and since it is supposed to be non-reinforced mortar, we limit tension resistance to $0.3 \mathrm{MPa}$, which is a strongly conservative hypothesis in our case. The thermal performances are calculated with a geometrical mean, taking into account a security factor corresponding to member thickness irregularities that can be expected at the nodes when extruding such a structure.

The parameters are then (1) the type of space truss grid (see next section), (2) the truss thickness and (3) the bars diameters. The compared objectives are (a) additional insulation need (if needed, to reach target $\mathrm{U}$-value of $0.09 \mathrm{~W} \mathrm{~m}^{-2} \mathrm{~K}$ ), (b) mechanical efficiency and (c) surface weight of the wall.

\section{Grid Comparison}

Different grid topologies are investigated for the concrete space truss in terms of structural efficiency and compatibility with the proposed manufacturing method. These topologies are taken from the edges of a space tessellation of the bounding box of the wall, so that a geometric duality with the polyhedral insulating blocks can be obtained. Considering that fresh mortar will be printed on the blocks, some geometrical configurations are to be avoided. We have retained five potential topologies that does not present internal vertical members that would be hard to print. They are listed in Table 1 and shown on Fig. 2.

Table 1. Grid types

\begin{tabular}{l|l|l}
\hline Name & Description & Maximum node valence \\
\hline TriPr & Triangle prisms & 7 \\
\hline SemiOcTe & Semi-octahedra/tetrahedra & 8 \\
\hline OcTe & Octahedra/tetrahedra & 9 \\
\hline CnTri & Counter running triangle (tetrahedra) & 10 \\
\hline Hexa & Hexagonal pyramids & 12 \\
\hline
\end{tabular}




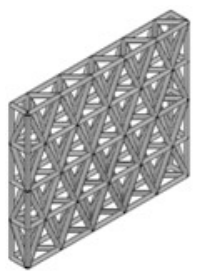

CnTri

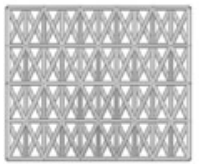

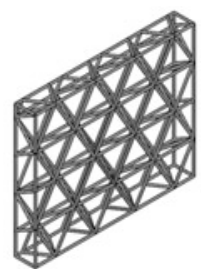

OcTe

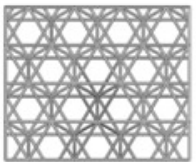

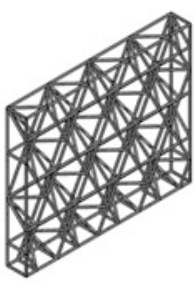

Hexa

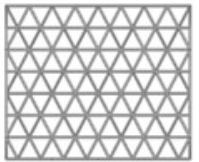

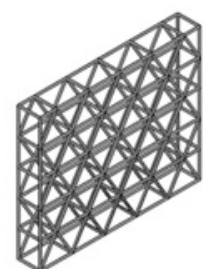

TriPr

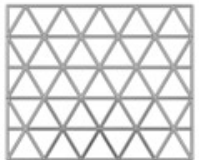

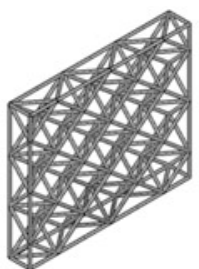

SemiOcTe

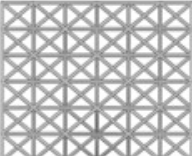

Fig. 2. Grid topologies

We suppose that the lateral and horizontal frontier are supported, as for constrained masonry, and impose three load cases corresponding respectively to self-weight, overall lateral pressure (wind) and a specific horizontal point load of $2 \mathrm{kN}$. This last case has been taken from design methods for guardrails. The need for such verification comes from the attainable lightness for the wall (around $50 \mathrm{~kg} \mathrm{~m}^{-2}$ ). Traditional block work construction is indeed very often far more resistant that one could need, in non-seismic areas. In our case, this additional load case is critical. From possible structural failures - stresses in material, local and global buckling - in every case the tensile stress in members is the one critical. We conduct a heuristic calculation on every topology with Grasshopper plugin Octopus, plotting performances in a three dimensional space corresponding to the following quantities:

$\mathrm{X}$ axis Additional insulating thickness to reach target $\mathrm{U}$-value $(\mathrm{cm})$

$\mathrm{Y}$ axis Maximum tensile stress in members $(\mathrm{MPa})$

$\mathrm{Z}$ axis Weight $\left(\mathrm{kg} \mathrm{m}^{-2}\right)$

On Fig. 3 are plotted the Pareto fronts of each topology. The colors map additional information on them.

On all the left graphs is represented a color scaled mapping of the overall thickness of the wall (truss + additional insulation), typically varying from about $40 \mathrm{~cm}$ (green) to $90 \mathrm{~cm}$ (dark blue). The middle graphs show the points on the Pareto fronts below the maximum tensile stress of $0.3 \mathrm{MPa}$ in green that are all the acceptable solutions, the others are in red. Finally the graphs on the right isolate the ten lightest (weight criteria on axis z) of such feasible individuals. The hexagonal pyramids solution would not allow an acceptable tensile stress for decent weight so the results are not plotted and the topology rejected.

On Table 2 are listed the performances of the best solution for each topology.

On Fig. 4 are plotted the weight variations with overall thickness for the ten best solutions of each configuration. We observe that the Triangle Prisms topology is the 


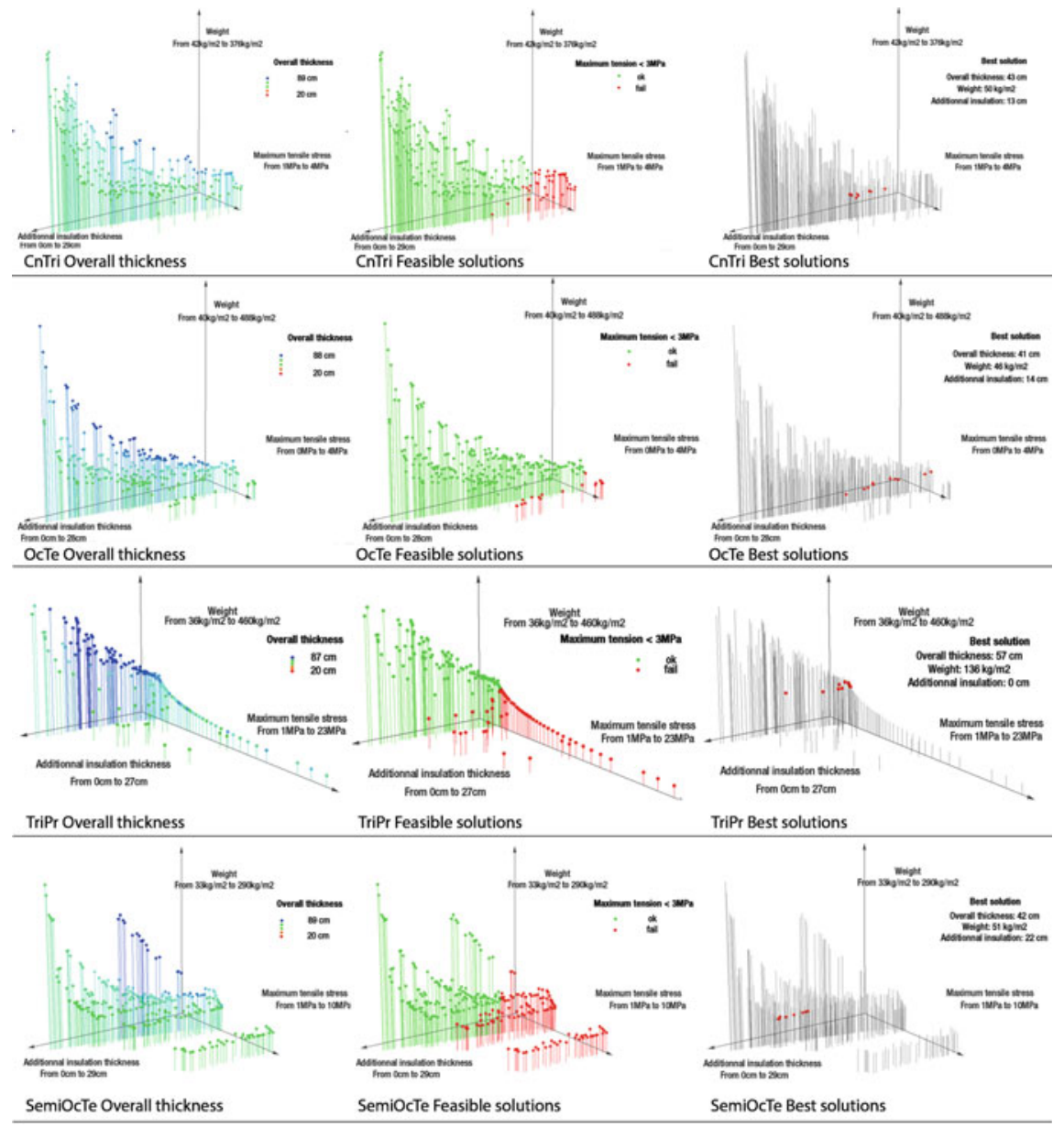

Fig. 3. Pareto fronts comparison

Table 2. Optimal grids comparison

\begin{tabular}{l|l|l|l|l}
\hline Name & Thickness $(\mathrm{cm})$ & Weight $\left(\mathrm{kg} \mathrm{m}^{-2}\right)$ & Add. insulation $(\mathrm{cm})$ & Valence max \\
\hline TriPr & 76 & 136 & 0 & 7 \\
\hline SemiOcTe & 42 & 51 & 22 & 8 \\
\hline OcTe & 41 & 46 & 14 & 9 \\
\hline CnTri & 43 & 50 & 13 & 10 \\
\hline
\end{tabular}




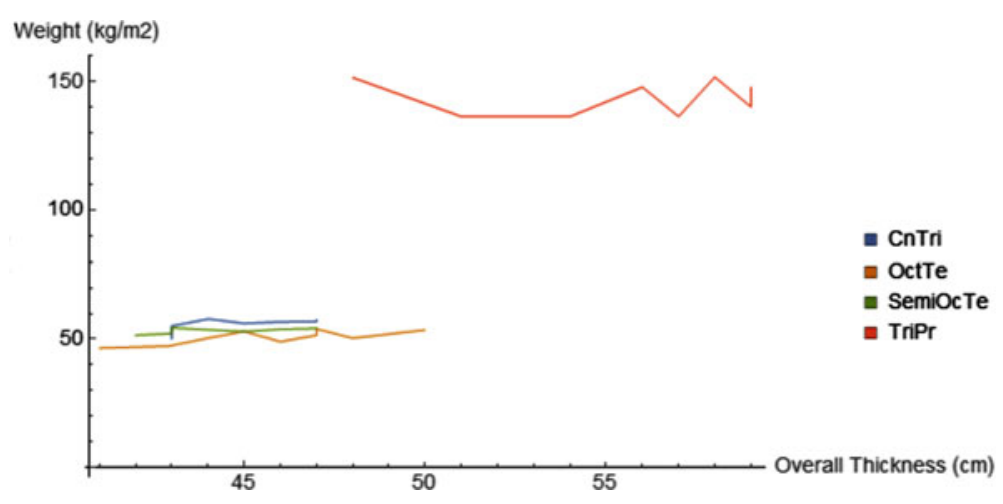

Fig. 4. Ten best individuals' weight/overall thickness

worst configuration. The three other solutions are of similar results for our criteria, therefore the best choice is the Semi Octahedra/Tetrahedra configuration that exhibits the lowest node valence, useful for fabrication purpose.

\section{Results and Discussion}

We have presented here a new fabrication concept for light weight masonry walls of novel structural and thermal performances. The key aspect of it is to replace the traditional rectilinear breezeblock and mortar system by the printing of a mortar space truss structure, supported by polyhedrically shaped insulating blocks. This system takes part in the global effort toward automation in construction, to build better and more efficiently, to face current needs in housing and to reduce environmental impact. This generic problem can be addressed at three main levels: a change in building materials themselves, a better geometrical control of build objects, and/or a transformation of building systems. Our proposition is a renewal of traditional constrained masonry system, by allowing it to handle more efficient geometries such as space trusses. The result is a relatively simple assembly system that allow great performances of produced objects, as shown in Table 3.

Table 3. Performance comparison with other systems

\begin{tabular}{l|l|l|l}
\hline Wall system & Overall thickness $(\mathrm{cm})$ & Weight $\left(\mathrm{kg} \mathrm{m}^{-2}\right)$ & U-value $\left(\mathrm{W} \mathrm{m}^{-2} \mathrm{~K}\right)$ \\
\hline Breeze blocks & 40 & 180 & 0.1 \\
\hline Cellular concrete & 56 & 150 & 0.09 \\
\hline Pre-wall & 42 & 220 & 0.15 \\
\hline Printed truss & 42 & 50 & 0.09 \\
\hline
\end{tabular}


We conclude with a comparison with three other systems engaging concrete:

1. A traditional breeze block and mortar system, with $20 \mathrm{~cm}$ thick blocks $\left(25 \times 50 \mathrm{~cm}^{2}\right)$, and $1 \mathrm{~cm}$ mortar joint. With a performance insulator, like graphite polystyrene $\left(\lambda=0.031 \mathrm{~W} \mathrm{~m}^{-1} \mathrm{~K}^{-1}\right)$, a $20 \mathrm{~cm}$ layer is needed to reach target thermal performance.

2. A cellular concrete solution, $36 \mathrm{~cm}$ thick with $20 \mathrm{~cm}$ graphite polystyrene.

3. A pre-wall system consisting in a insulating mold of one $5 \mathrm{~cm}$ and one $25 \mathrm{~cm}$ insulation layer connected with steel bars, for casting a $12 \mathrm{~cm}$ thick concrete wall. Minimum $\mathrm{U}$ value is of $0.15 \mathrm{~W} \mathrm{~m}^{-2} \mathrm{~K}$.

The presented building system can not only be seen as a renewal of traditional masonry, but also as a generalization of "concrete printing", when this term denotes only the stacking of extruded mortar laces to form an object. In fact, this technique, although studied under the assumption that it is an effort toward "free-form construction" (Pegna 1997), depending on its explicit materialization, allows a certain family of shapes to be build, in a certain way, and with a given technological mean. We have proposed in another paper (Duballet et al. 2017) a classification of generalized robotic extrusion building methods, taking into account not only the extrusion itself, but also different types of support and assembly strategies, as well as scale considerations. From that perspective, the present system is a generalized mortar printing approach, mixing assembly of external elements during the process, and making use of printing support left in place. Such considerations help us understand more precisely what those robotic techniques can become for today's construction.

Acknowledgements. The authors would like to thank V. Esnault at LafargeHolcim Research and Development for fruitful discussions. Support from LafargeHolcim is gratefully acknowledged.

\section{References}

Bosscher, P., Williams, R.L., Bryson, L.S., Castro-Lacouture, D.: Cable-suspended robotic contour crafting system. Autom. Constr. 17(1), 45-55 (2007)

Duballet, R., Baverel, O., Dirrenberger, J.: A proposed classification for building systems based on concrete 3D printing. Autom. Constr. (2017)

Duballet, R., Gosselin, C., Roux, P.: Additive manufacturing and multi-objective optimization of graded polystyrene aggregate concrete structures. In: Design Modelling Symposium (2015)

Feng, P., Meng, X., Chen, J.-F., Ye, L.: Mechanical properties of structure 3D printed with cementitious powders. Constr. Build. Mater. 93, $486-497$ (2015). http://www.sciencedirect. com/science/article/pii/S095006181500690X

Gosselin, C., Duballet, R., Roux, P., Gaudillière, N., Dirrenberger, J., Morel, P.: Large-scale 3D printing of ultra-high performance concrete- a new processing route for architects and builders. Mater. Des. 100, 102-109 (2016). http://www.sciencedirect.com/science/article/pii/ S0264127516303811

Khoshnevis, B.: Automated construction by contour crafting-related robotics and information technologies. Autom. Constr. 13(1), 5-19 (2004) 
Le, T.T., Austin, S.A., Lim, S., Buswell, R.A., Gibb, A., Thorpe, T.: Mix design and fresh properties for high-performance printing concrete. Mater. Struct. 45, 1221-1232 (2012a). doi:10.1617/s11527-012-9828-z

Le, T.T., Austin, S.A., Lim, S., Buswell, R.A., Law, R., Gibb, A.G.F., Thorpe, T.: Hardened properties of highperformance printing concrete. Cem. Concr. Res. 42(3), 558-566 (2012b)

Lim, S., Buswell, R., Le, T., Wackrow, R., Austin, S., Gibb, A., Thorpe, T.: Development of a viable concrete printing process. In: Proceedings of the 28th International Symposium on Automation and Robotics in Construction (ISARC2011), pp. 665-670 (2011)

Lim, S., Buswell, R.A., Le, T.T., Austin, S.A., Gibb, A.G.F., Thorpe, T.: Developments in construction-scale additive manufacturing processes. Autom. Constr. 21(1), 262-268 (2012)

Pegna, J.: Exploratory investigation of solid freeform construction. Autom. Constr. 5(5), 427437 (1997) 